\title{
PROPOSTES PER A UNA MILLOR EXPLOTACIO DE LES DADES PADRONALS DELS MUNICIPIS DE CATALUNYA
}

\author{
Edouard Conte \\ (University College of London) \\ Lluís Flaquer \\ (Universitat Autònoma de Barcelona)
}

\section{INTRODUCCIO}

Les dades padronals constitueixen una font de riquesa desaprofitada, tant de cara a la planificació dels serveis socials i culturals com de cara a la millora del nostre coneixement de l'estructura social de la Catalunya d'avui i de la seva transformació. En general, observem que els ajuntaments no han procedit a un tractament informàtic analític de les dades proporcionades pels padrons fins a l'any 1981. L'objecte d'aquest report preliminar ${ }^{1}$ és encetar la discussió sobre com explotar millor els fons padronals que tenim a la nostra disposició. Així mateix, esperem plantejar unes bases tècniques i metodològiques per a facilitar la constitució de serveis de seguiment de l'evolució de l'estructura social catalana, en particular per part dels mateixos ajuntaments que s'encarreguen de la recollida de dades i de llur actualització anual.

Presentem ací una sèrie de propostes en aquest sentit: a) per a enriquir

1. Aquest treball s'ha d'emmarcar dins d'un programa més ampli d'estudi de la realitat social catalana que se centra principalment sobre les transformacions actuals de les estructures familiars i comunitàties. El present report s'adreça en primer lloc a aquelles persones preccupades pel millorament dels serveis administratius $i$ socials. 
el tractament de padrons tan sols parciaiment codificats; b) per a otientar el tractament futur de les dades proporcionades per les tectificacions padronals; $i$ c) per a establir una codificació inicial més adequada i rica de padrons futurs.

En el cos d'aquest treball procurarem illustrar cada proposta metodològica amb exemples que palesin algunes de les seves possibles aplicacions pràctiques.

\section{SUGGERIMENTS PER AL TRACTAMENT DE DADES}

Molts ajuntaments, a causa de manques i restriccions pressupostàries i tècniques, s'han acontentat a extreure del padró tan sols una sèrie de sumes $\mathrm{i}$ a indicar els percentatges de persones que responen a tal o tal criteri. Cal subratliar, però, que les dades padronals poden permetre, gràcies a unes tècniques analítiques relativament senzilles, d'identificar anb una certa precisió categories de la població que tenen unes necessitats de serveis socials $i$ culturals específiques $o$, per altra banda, unes àrees de problemes i preocupacions que tenen una importància ditecta per a l'administració pública. Nogensmenys, el rendiment que podem derivar de la lectura directa de les conclusions extretes de l'anàlisi d'un sol padró està subjecte a limitacions importants.

En primer lloc, el padró és un instrument general amb finalitats bàsicament censals. Per tant, el nombre de dades que es pot sollicitar als enquestats és forçosament reduit. A més, la majoria d'informacions padronals no té un sentit absolut en la mesura que llur pertinència només apareix quan es relacionen amb altres dades que, en molts casos, no estan incloses en el padtó. Per fi, la imatge que ens proporciona el padró és una «instantània fotogràfica» que reflecteix certs vessants de l'estructura social. Per tal d'obtenir una visió més completa i explicativa d'aquesta última, cal introduir una dimensió temporal o "cinematogràfica» en la lectura i la interpretació de les dades padronals. És a dir, convé efectuar un examen comparatiu de dos o més padrons successius. Més endavant insistitem particularment en la importància que té la consideració cronològica del problema per tal de completar les dades que es refereixen a un lloc $i$ a un moment precisos.

A fi de demostrar la utilitat d'aquest enfocament, proposem a continuació una sèrie d'associacions estadístiques entre elements d'informació que considerem com a bàsiques per a l'aprofitament del fons de dades padronals, si és que volem superar la mera tabulació estadística descriptiva. 
Per tal d'operar amb uns nivells minims de seguretat que, malauradament, to sempre s'han garantit, és imprescindibie un control de qualitat previ de les dades al nostre abast en els mateixos fulls padronals o bé enregistrades sobre suport informàtic (cintes magnètiques, discs...). Així mateix, convé fer algunes observacions sobre els criteris que presideixen la confecció dels padrons, no sempre totalment encertats al nostre entendre. A fi de procedir a la interrelació de tots els elements d'informació d'importància immediata per a l'administració i la gestió públiques continguts al padró, és necessari disposat d'un corpus de dades exhaustivament codificat, és a dir, informatitzable, cosa que, dissortadament, no s'ha pogut realitzar fins ara d'una manera general pel que fa a l'explotació del darrer padró - 1981- a Catalunya. És per això que establim més endavant unes propostes de codiffcació d'aquelles dades que fins avui no s'han acostumat a explotar informàticament.

Hem observat una marcada tendència en aquest àmbit a acontentar-se amb l'explotació parcial de les dades obtingudes, a través de procediments de mostratge. El fet de recórrez a mostres reduildes, que moltes vegades no passen del $5 \%$, pot impossibilitar la percepció i el millor enfocament, ja sigui de les especificitats del perfil demogràfic i sòcio-econòmic de comunitats petites, de barris de ciutats més grans, ja sigui de problemes que, tot i només concernit categories numèricament restringides de la població, poden tenir implicacions generals i revestir una gravetat que no es pot menystenir. Recomanem, per tant, cada vegada que sigui necessari i materialment possible, treballat amb poblacions exhaustives 0 , si més no, amb mostres prou àmplies per permetre la detecció de necessitats no inicialment considerades. En cas contrari, l'«anàlisi estadística» esdevé una confrrmació pura i simple de les previsions originàries, més o menys conscients, dels investigadors.

\section{Depuració de les dades}

A l'Apèndix I presentem la llista integral de les informacions elementals que inclou el padró municipal d'habitants d'una gran ciutat de Catalunya, elabotat l'any 1981. Segons una estimació efectuada pels serveis tècnics d'aquest municipi, ens trobem confrontats a unes taxes d'error força elevades. A tall d'exemple, i sota reserva d'ulteriors verificacions, constatem els percentatges següents: 
- Errors en l'adreça (sobretot referits al número de carrer): $6 \%$.

- Errors en la recollida de l'any de naixement: $5 \%$.

- Diferències notables en l'any d'arribada a Catalunya: $8 \%$.

De fet, aquests resultats són, tot i considerant-los individualment, elevats. Apuntem que, en principi, la tolerància d'inexactituds en un padró d'aquesta mena no ha de superar 1'1 \%. És clar que a partir del moment que es donen equivocacions tan freqüents, en el cas de voler correlacionar dues o més variables, la taxa d'error esdevé alarmant i els resultats de I'anàlisi del padró inutilitzables.

Un padró pot costar molts milions. Cal, per tant, assegurar uns controls rigorosos en efectuar-se l'empadronament, tant a l'hora de la recollida dels fulls censals per part de l'agent com a l'hora de fer-ne una revisió, que hautia de ser sistemàtica i anterior a la cloenda del cens.

Per desgràcia, els errors de transcripció poden empitjorar aquesta situació quan s'enregistren les dades manuscrites sobre suport informàtic. En el cas que citem, el nivell d'errors que es dóna, segons verificacions dutes a terme per tècnics d'un centre de càlcul, pot oscillar entorn del $10 \%$ : Esperem que aquest cas més aviat sigui una excepció a Catalunya... i que illustri a bastança la necessitat imperiosa de procedir a un control de qualitat dels padrons municipals. La responsabilitat d'aquesta tasca competeix a l'administració pública.

\section{Algunes remarques sobre el disseny dels fulls padronals}

Si bé existeixen certes variacions en la presentació dels fulls padronals segons els municipis, l'examen d'uns quants fulls suggereix certes remarques de cara a l'organització de les preguntes formulades:

a) Per supèrflua que pugui semblar, la inclusió de la data i del lloc de matrimoni dels enquestats permetria una anàlisi moit més adequada de l'evolució de les estructures familiats, de la composició dels grups residencials, de la fertilitat i la natalitat i dels fluxos migtatoris que tant han modificat la composició de la població de Catalunya en els últims trenta anys. No cal dir que tots aquests temes, a més de llur transcendència en el coneixement quantitatiu i qualitatiu de l'estructura social, tenen implicacions directes per a la previsió escolar, cultural, sanitària i, evidentment, de cara a les necessitats d'habitatge.

b) Val a dir que, al nostre entendre, el qüestionari sobre el nivell d'instrucció (vegeu l'Apèndix I, punt 28) conté certes deficiències relatives. 
Constatem que per a algunes comunitats de la Corporació Metropolitana de Barcelona, els ciutadans inclosos en les subcategories 1 i 2 («no sap llegir ni escriure o hi té dificultats» 1 «primària incompleta») arriben a tepresentar una part substancial de la població que pot fins i tot superat la seva meitat. La formulació adoptada per a aquestes preguntes - sobretot la segona- pot ocultar certes realitats que interessa conèixer. Caldria distingir entre el cas en què els estudis primaris són incomplets perquè s'estan cursant $i$ el cas d'aquells individus, joves $i$ adults, que, havent-los deixat "penjats», han d'ésser considerats com a analfabets funcionals. Remarquem, però, que el fet de tenir els estudis primaris complets pot no ésser necessàriament signe d'una manca cultural. És del deure de cada ajuntament estudiar amb la deguda atenció possibles dèficits educatius d'aquesta magnitud $i$ importància socials.

Seria igualment de desitjar la inclusió dins d'aquest apartat d'una pregunta destinada a esbrinar l'impacte de l'analfabetisme en llengua materna, ja sigui aquesta la catalana o la castellana.

c) L'evaluació de la comprensió i la tstilització efectiva de la llengua catalana (vegeu Apèndix I, punt 29) exigeix una reflexió seriosa sobre la o les qüestions incloses pel que fa al cas en els fulls padronals. Preguntes del :ipus: «Enteneu el català?» inciten a taxes exageradament elevades de respostes positives, puix que poden fer aparèixer com a «inadequades» aquelles persones que hi contestin negativament. Els casos de municipis de la perifètia industrial de Batcelona on s'obtenen taxes de resposta positiva a l'entorn del $70 \%$ engendren un cert escepticisme... A més, el fet que aquesta dada sigui «veritat» o no, no té cap mena de sentit sociològic. La resolució d'aquesta qüestió requereix la intervenció de sociolingüistes qualificats. Permetem-nos, però, de rematcar que la multiplicació de matrimonis mixtos justifica per si mateixa l'establiment d'una distinció entre «llengua materna» i «llengua habitual d'interacció».

d) Existeixen certes tedundàncies entre les preguntes dels qüestionaris relatives a la «situació laboral» i la «condició sòcio-econòmica» (vegeu Apèndix I, punts $30 \mathrm{i} 33$, respectivament). La reiteració d'aquesta incongruència d'un padró a l'altre és, potser, explicable per la manca de revisió de les normes administratives que regulen el contingut dels padrons. Assenyalem que les economies realitzables en termes de tractament informàtic per l'eliminació de les redundàncies permetrien la inclusió de preguntes més significatives, com són, des del nostre punt de vista, les relatives a la celebració del matrimoni $\dot{i}$ als usos lingüístics. 


\section{Propostes per a la codificació de dades padronals no codificades}

Els fulls padronais, contràriament als fulls censais estatals, no comporten caseiles destinades a la informatització de les dades següents:

- Parentiu o relació amb el cap de casá o persona principal.

- El municipi, la província i, en el cas dels estrangers, el país d'otigen.

- La professió de l'individu i l'activitat econòmica de l'empresa on treballa.

Suggerim que en els propers padrons s'utilitzin els codis numèrics establerts per I'Institut Nacional d'Estadística per a la codificació d'aquestes dades.

Opinem igualment que l'adreça de l'empresa, tant si es troba situada o no en el mateix municipi, podria ser codificada d'acord amb els mateixos criteris emprats per a la localització de cada habitatge.

Tanmateix, ens sembla que la relació de parentiu amb el cap de famín lia té prou importància com per a fer-la digna d'una codificació més precisa, que permeti especificar millor l'estructura interna dels grups residencials $\mathrm{i}$ Ia seva variació en funció de criteris tan rellevants per a la planificació social com els d'edat i generació, lloc de residència, nivell d'instrucció, ús lingüístic o condició sòcio-econòmica.

La classificació que proposem ací té per objecte facilitar explotació fructífera d'aquestes dades i deriva de tres tipus d'informació:

a) La denominació de la relació de cada individu amb el cap de famí lia o persona principal; b) el sexe de la persona en qüestió; i c) la possible distància generacional entre el cap de casa i la persona en qüestió.

Cada persona considerada podrà designar-se gràcies a un codi de tres nombres que resumeix aquestes tres informacions. La taula adjunta indica el conjunt de referents possibles que permet aquesta classificació. Convé ara presentar els elements necessaris per a la lectura de la taula:

a) La primera columna dóna el codi numèric de cada categoria de relació entre una persona i el cap de casa o persona principal del grup tesidencial en el qual viu. La numeració que designa les relacions va d'1 a 17.

b) La segona columna dóna les designacions de les relacions existents entre els caps de casa o persones principals (de sexe indiferent) i les per- 


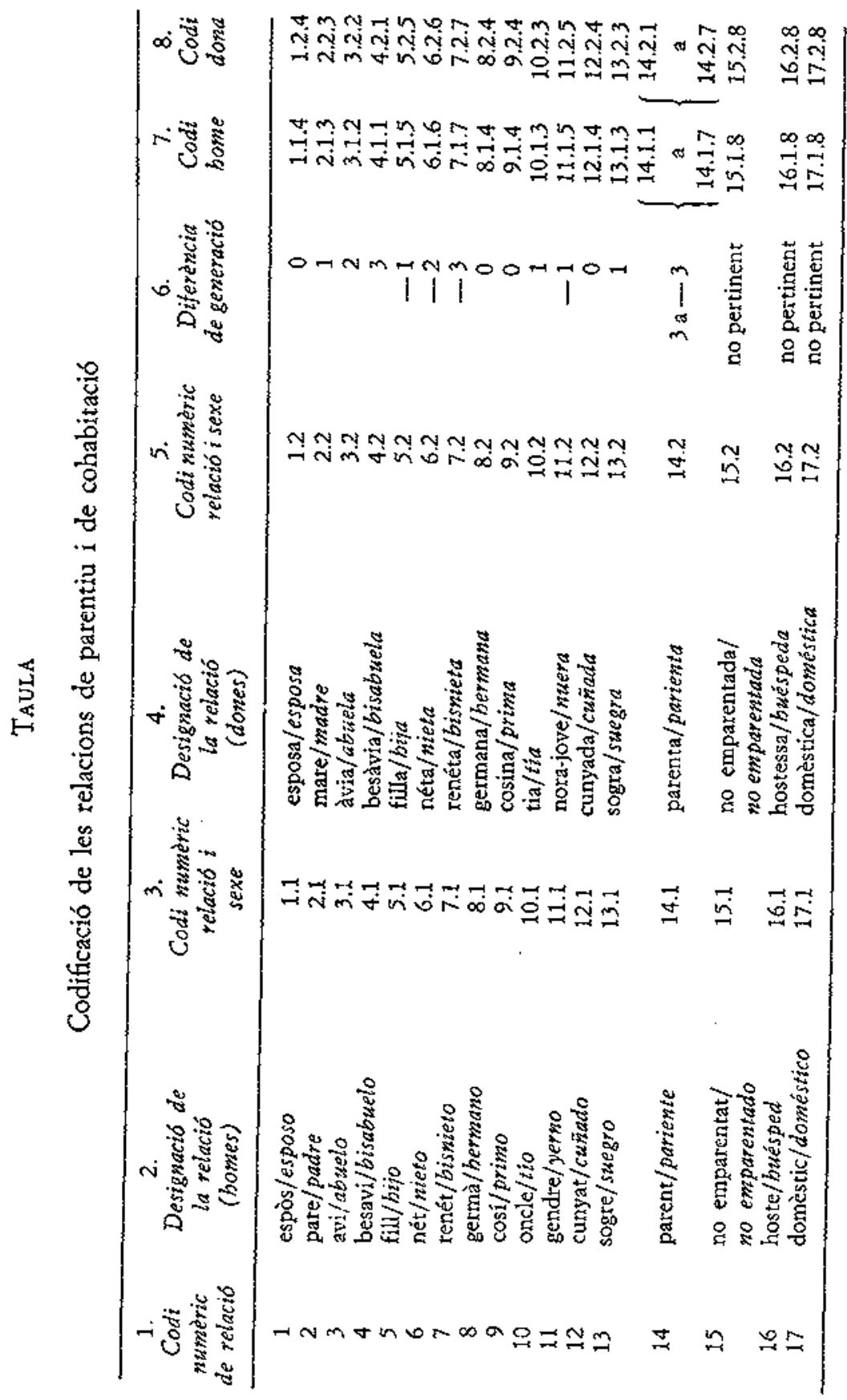


sones de sexe masculí, especificat per la xifra 1. A la designació catalana, correspon la seva traducció castellana.

c) La tercera columna dóna un codi que consta de dos nombres (verbigràcia, $2.1,13.1 \ldots$ ), el primer dels quals designa la categoria relacional i el segon el sexe masculí.

d) La quarta columna dóna les designacions de les relacions existents entre els caps de casa o persones principals (de sexe indifetent) i les persones de sexe femení, designat per la xifra 2. A la designació catalana, correspon la seva traducció castellana.

e) La cinquena columna dóna un codi que consta de dos nombres (verbigràcia, $3.2,7.2 \ldots)$, el primer dels quals designa la categoria telacional i el segon el sexe femení.

f) La sisena columna indica quina és la diferència generacional existent entre el cap de família o persona principal i la persona considerada, lligades ambdues entre elles per la relació especificada en les columnes 2 a 5 . Considerarem en el present context diferències generacionals que van de més tres (besavi/besàvia) a menys tres (renét/renéta) respecte d'un Ego (persona de referència) que és el cap de casa o persona principal.

g) La setena columna dóna un codi de tres nombres aplicable a les persones de sexe masculf. El primer nombre designa la categoria telacional (cf. columna 1). El segon es refereix al sexe de la persona (cf. columna 2). El tercer indica la diferència generacional existent entre el cap de casa o persona principal i la persona considerada en funció del codi numèric següent:

$\begin{array}{lll}\text { (besavis) } & \text { Generació més 3: } & 1 \\ \text { (avis) } & \text { Generació més 2: } & 2 \\ \text { (pares) } & \text { Generació més 1: } & 3 \\ \text { generació de referència } & \text { Generació 0: } & 4 \\ \text { (fills) } & \text { Generació menys 1: } & 5 \\ \text { (néts) } & \text { Generació menys } 2: & 6 \\ \text { (renéts) } & \text { Generació menys } 3: & 7 \\ \text { Quan el parentiu no hi intervé: } & 8\end{array}$

Cal remarcar que la diferenciació generacional no s'aplica a les categories relacionals (vegeu columna 1) 15 (no emparentat), 16 (hoste) i 17 (domèstic). Per tant, el codi generacional numèric no és pertinent en aquests casos.

b) La vuitena columna dóna un codi de tres nombres aplicable a persones de sexe femení. El primer nombre designa la categoria relacional (vegeu columna 1), cora a la columna 7 . El segon designa el sexe de la 
persona (vegeu columna 2). El tercer indica la diferència generacional entre la persona en qüestió i el cap de casa o persona principal, en funció de la codificació indicada a l'apartat precedent.

Un cop fets els suggeriments que ens semblen pertinents per a la codificació dels elements d'informació expressats amb totes les seves llettes (vegeu primera remarca $\left({ }^{*}\right)$ de l'apèndix 1), podem passar a la presentació de les intertelacions bàsiques en què es podria recolzar el coneixement de l'estructura demogràfica i sòcio-econòmica del municipi.

Per descomptat, les propostes que fem a continuació no s'han d'interpretar d'una manera estricta i uniforme, sinó que els funcionatis i investigadors interessats a posar-les en pràctica haurien de fer gala de flexibilitat i d'imaginació. Cal tenir en compte, és clar, entre molts altres factors tocalment canviants, la variable determinant que constitueix la grandàtia de la població, sobretot pel que fa a l'eventual pertinència de nombroses subcategories. Les poblacions de gran dimensió donen la possibilitat de filar molt prim, donada la quantitat de casos inventariats. En canvi, en comunitats petites l'anàlisi estadística mai no pot suplix el tracte directe amb la gent.

\section{Interrelacions de variables fonamentals}

A partir del moment en que s'ha efectuat l'empadronament dels ciutadans d'un municipi, creiem profitós que cada ajuntament tregui una rendibilitat màxima, tant social com administrativa, de la substancial inversió realitzada a base de constituir un fons documental a l'abast tant dels funcionaris públics, dels treballadors socials, del personal sanitari i dels planificadors i cientifics socials, com dels membres del públic en general (els quals, després de tot, financen l'operació).

Llista de taules creuades fonamentals de dues variables que convé establir a partir de les informacions padronals (vegeu apèndix I).

1. Interrelacionar la distribució de la població segons el sexe (19) i les informacions següents:

a) L'estat civit (20).

b) El municipi d'origen (21). ${ }^{2}$

2. Habitualment, en les distribucions estadístiques producte de l'anàlisi dels padrons, hom descarta d'entrada com a vatiable pertinent el lloc de naixement, segura- 
c) La provincia d'origen (22).

d) La regió d'origen. ${ }^{3}$

e) Durada de la residència al municipi (24).

f) Durada de la residerncia a Catalunya (25).

g) Realitzacio d'estudis regulars o lliures (27).

b) Nivell d'instrucció (28). (Es distingeixen les subcategories 1 a 8.)

i) Situació laboral (30). (Es distingeixen les subcategories 1 a 9.)

i) Activitat de l'empresa (31). (Es distingiran les activitats de cada empresa segons la categorització numèrica de I'INE.)

k) Professió (32). (Es distingiran les diferents professions segons la categorització emprada per l'INE.)

l) Condició sòcio-econòmica (33). (Es distingeixen les subcategoties 1 a 9.$)$

2. Intertelacionar l'estat civil (20) i les informacions següents:

a) El municipi d'origen (21).

b) La província d'origen (22).

c) La regió d'origen.

d) Durada de la residència al municipi (24).

e) Durada de la residència a Cataltnya (25).

f) Realització d'estudis regulars o lliures (27).

g) Nivell d'instrucció (28). (Es distingeixen les subcategories 1 a 8.)

b) Situació laboral (30). (Es distingeixen les subcategories 1 a 9.)

i) Activitat de l'empresa (31). (Es distingiran les activitats de cada empresa segons la categorització numètica de l'INE.)

i) Professió (32). (Es distingiran les diferents professions segons la categorització emprada per l'INE.)

ment a causa de la multiplicitat de modalitats que representa. Amb tot, i tenint en compte les possibilitats obertes avui per la informàtica, ta consideració del lloc d'origen és d'una gran importància, puix que ofereix les bases per a seconstituit amb exactitud els fuxos migtatoris que han afectat cada municipi. Assenyalem que el creuament entre les dades sobre immigració i emigració amb especificació del lloc de naixement, i les sèries de dades anàlogues $\mathrm{i}$ complementàries procedents d'altres municipis de l'Estat amb els quals es mantenen estretes relacions migiatòties, petmetria avaluat la naturalesa dels lligams humans $i$ economics entre comunitats emissores i teceptores.

3. No proposem ací una classificació de les comunitats autònomes espanyoles, atès que el debat legislatiu sobre els estatuts d'autonomia encara està per cloure (gener de 1983). Des del moment que la creació de les entitats autonòmiques no implica la desaparició de l'estructura provincial, l'obtenció de les dades relatives a les regions autonomes es pot aconseguir per simple agregació de les informacions relatives a les unitats provincials pertinents. 
Les dades padronals dels municipis de Catalunya

k) Condició sòcio-econòmica (33). (Es distingeixen les subcategories 1 a 9.$)$

3. Interrelacionar el municipi de naixement i les informacions següents:

a) Durada de la residència al municipi (24).

b) Durada de la residència a Catalunya (25).

c). Nivell d'insirucció (28). (Es distingeixen les subcategories 1 a 8.)

d) Situació laboral (30). (Es distingeixen les subcategories 1 a 9.)

e) Activitat de l'empresa (31). (Es distingiran les activitats de cada empresa segons la categorització numèrica de l'INE.)

f) Professió (32). (Es distingiran les diferents professions segons la categorització emprada per l'INE.)

g) Condició sòcio-econòmica (33). (Es distingeixen les subcategories 1 a 9.$)$

Per tal com les modalitats de la categoria «municipi de naixement» són molt nombroses, sobretot en relació a les comunitats de població reduïda, proposem les agregacions de dades individuals següents:

1) Persones nascudes al mateix municipi.

2) Persones nascudes a la resta de la província.

3) Persones nascudes a la resta de Catalunya.

4) Persones nascudes a cadascuna de les províncies espanyoles, llevat de la del municipi.

5) Persones nascudes a cadascuna de les comunitats autònomes de l'Estat espanyol, lievat de la de Catalunya.

6) Persones de nacionalitat espanyola nascudes a l'estranger.

7) Persones de nacionalitat estrangera nascudes a l'estranger.

8) Persones de nacionalitat estrangera nascudes a Espanya.

4. Interrelacionat el nivell d'instrucció (28) i les informacions se. güents, tot distingint-ne les subcategories 1 a 8 :

a) Situació laboral (30). (Es distingeixen les subcategoties 1 a 9.)

b) Activitat de l'empresa (31). (Es distingiran les activitats de cada empresa segons la categorització numèrica de l'INE.)

c) Professió (32). (Es distingiran les diferents professions segons la categorització emprada per l'INE.)

d) Condició sòcio-econòmica (33). (Es distingeixen les subcategories 1 a 9.$)$ 
Quin serà el resultat directe d'aquestes operacions? Obtindrem un seguit de taules, la lectura de les quals farà palesos els principals trets de l'estructura demogràfica i sòcio-econòmica de la comunitat en qüestió.

Aquest conjunt de taules, en l'àmbit d'un ajuntament democràtic, hauria de servir, si més no, per a dues fmalitats primordials:

- D'una banda, la constitució d'un fons documental bàsic a la disposició del públic en genetal i de tots els qui s'interessin per al coneixement de l'estructura social.

- De l'altra banda, la identificació, per part de l'administració, de necessitats no expressades $\mathrm{i}$ de focus de problemes inicialment no percebuts, que, si no són tractats a temps, poden esdevenir potencialment greus.

La lectura d'una taula pot no ser, en si, significativa. Per tal d'interpretar degudament una taula, cal contraposar-la a d'altres distribucions ja conegudes referides a entitats administrativo-geogràfiques més àmplies que ofereixin punts de referència possibles a fi de detectar peculiaritats locals que divergeixen significativament de les mitjanes acceptables.

Posem un exemple. Tothom coneix per la premsa i per fonts estadístiques estatals i provincials l'evolució aproximada de les taxes d'atur. Ara bé: l'examen detingut d'aquest problema, prenent com a unitat de referència el barri o la secció, pot revelar bosses insospitades $\longrightarrow$ no reconegudes- d'atur. En efecte, la convergència de diversos factors relatius a manques socials, com ara elevades taxes d'analfabetisme, una alta incidència de determinats tipus d'atur sectorial, i una baixa qualificació professional, que dificulti la reconversió i el reciclatge, units a la presència d'altres dè. ficits com poden ser certes mancances en l'àmbit de l'habitatge i dels equipaments collectius, pot exacerbar les fonts de conflicte social.

La utilització sistemàtica de la lectura comparativa i circumstanciada de les dades hauria de servir com a eina de detecció de focus de margina* ció social que, si bé no són tan aclaparadors com l'esmentada situació, poden romandre inadvertits.

Fins aquí hem anat considerant l'individu com a unitat d'anàlisi de base car, evidentment, és el nivell d'informació més elemental en la comprensió de la societat. Tanmateix, això no exclou la necessitat de tenir en compte un segon nivell sobre el qual el full padronal ens dóna una informació imprescindible per a l'enteniment del teixit social: la distribució en una població dels diversos tipus de grups residencials. Malgrat tot, com ja hem esmentat més amunt, el padró no és més que una eina limitada que ens forneix un "clixé fotogràfic» d'una comunitat en un moment determi. nat. És per això que cal completar la visió que ens proporciona mitjançant 
la consideració de la dinàmica social, la qual es desenvolupa, en part, a través de la transformació de les estructures i de les pautes tesidencials.

Tractarem d'enfocar certs aspectes transcendents d'aquesta problemàtica en tres apartats:

1. Una proposta de classificació dels grups residencials.

2. Suggeriments per a l'explotació de les dades contingudes en les rectificacions padronals.

3. Mesures que podrien facilitar el seguiment de les transformacions bàsiques de l'estructura social per l'ad’ministració pública.

\section{PROPOSTA DE CLASSIFICACIÓ DELS GRUPS RESIDENCIALS}

En aquesta secció intentarem lligar l'anàlisi de les característiques personals amb la forma com els individus s'agrupen per formar unitats tesidencials més o menys permanents. La classificació de les relacions de parentiu o de convivència de cada individu amb el cap de casa o persona principal del grup domèstic en el qual viu és el pas preliminar imprescindible per a:

1. La reconstitució de la composició de cada grup residencial en termes relacionals.

2. A partir d'aquesta operació, l'establiment de les pautes residencials que caracteritzen una comunitat.

3. L'estudi de les associacions existents entre les dites pautes $i$ altres aspectes de l'organització sòcioeconòmica, la qual cosa al seu torn es pot realizzar a dos nivells: a) cercant la possible correlació que preval entre una modalitat residencial determinada i certes característiques personals dels seus membres; i b) establint la correlació entre determinades modalitats residencials i trets collectius de la població, que poden ésser o no contin. guts en el padtó.

Per tal de poder realitzar aquestes operacions, cal disposar primer d'una tipologia adequada dels grups residencials. Són lloables els intents que ha fet I'INE en aquest sentit a partir de 1970. El cens de població d'Es. panya d'aquesta data distingia entre cinc tipus de «família»:

a) Ltars sense nucli familiar (una o unes quantes persones que ocupen un habitatge).

b) Famílies nuclears reduides (de 2 a 5 membres). 
«Papars»: Revista de Sociologia

c) Famúlies nuclears nombroses (més de 5 membres).

d) Famílies nuclears ampliades (un nucli familiar amb altres parents, hostes, etc.).

e) Famílies plurinuclears (amb dos o més nuclis familiars).

Cal subratliar Ia insuficiència d'aquesta tipologia en certs aspectes. En prime: \loc, notem la utilització gratuïta del terme «família», amb diferents sentits, per a designar allò que en propietat s'haurien d'anomenar grups residencials. El concepte de familia implica l'existència d'un lligam matrimonial o de parentiu, mentre que el de grup residencial és més genèric $i$ inclou a la vegada altres menes de convivència que poden $o$ no fonamentar-se en el matrimoni. Remarquem igualment la falta de referència explícita en els punts $d)$ i $e$ ) a les diferències de generació, que resulten importants en l'àmbit de la planificació social.

En darrer lloc, la distinció entre les subcategories b) i $c$ ) és metodològicament redundant, per tal com no existeix cap diferència estructural entre una família de 4 o 6 fills, i ideologicament perillosa, en la mesura que $\mathrm{fa}$ referència implícita al nombre d'infants com a factor de contrastació qualitativa entre famílies més o menys prolífiques. En canvi, hauria estat desitjable diferenciar entre farnílies nuclears que inclouen ambdós pates i aquelles afectades per la desaparició, per mort o separació, d'un d'ells (les quals presumiblement queden englobades al calaix de sastre de la categoria $a$ ), $\mathrm{i}$ que tanta incidència tenen $\mathrm{i}$ tindran en el futur.

Fetes aquestes observacions crítiques, convé formular una proposta positiva per a la classificació dels grups residencials, que tingui en compte els esmentats factors.

Especifiquem, per començat, els criteris que han presidit aquesta classificació. Partim d'una dicotomia entre la presència i l'absència de relacions socials. En cas negatiu es tracta de persones solitàries. En cas afirmatiu pot ser que la relació sigui o no sigui de parentiu. Si no ho és, ens trobem amb un collectiu residencial de persones no vinculades per afinitat o consangtinitat (presó, internat, caserna, convent, grup d'arnics, etc.). ${ }^{4}$ Si ho és, es poden donat diversos casos:

a) Absència de nucli matrimonial. ${ }^{5}$ Aquesta modalitat pot comportar, de fet, almenys dues variants:

4. Aquests factors posen en relleu la importància de la cura que cal tenir a l'hota de l'empadronament quant a la distincío entre presents, absents $i$ transeünts, essent aquesta una condició prèvia de l'evitació de duplicitats.

5. Considerem, per analogia, nuclis «matrimonials» aquells que de fet són de cohabitatge, és a dir, no formalitzats pel vincle matrimonial. 
1. Cellules parentals (CP), definides com a conjunts residencials formats per un pare o bé una mare i flls seus.

2. Persones relacionades sense nucli (PRSN), que inclouen totes les altres combinacions possibles.

b) Presència d'un sol nucli mattimonial que dóna loc a la modalitat nuclear $(\mathrm{N})$.

c) Presència de dos (o tarament més) nuclis matrimonials vinculats per un lligam de filiació $i$, per tant, situats a nivells generacionals difetents, que dóna origen a la modalitat troncal (T').

Hi ha alguns d'aquests casos esmentats en què és pertinent, tant des del punt de vista estructural com des del sociològic, distingir entre les formes elementals $i$ les expandides de les configuracions que representen. Altrament dit, les modalitats $(a, 1),(b)$ i ( $c$ ) poden presentar-se en la seva forma elemental, o sia amb la presència dels elements míninas que determinen la seva estructura. D'altra banda, poden admette la incorporació d'altres membres (parents, hostes, servents). La forma elemental de les cèdules parentals està constituiida per la sola presència d'un pare/mate amb fills seus, la de la modalitat nuclear per la presència d'una sola parella i la de la modalitat troncal per la presència de dues parelles situades en nivells generacionals successius i vinculades per un lligam de filiació. Cal notar, però, que la forma elemental $\mathrm{CP}$ es distingeix de les formes elementals $\mathrm{N} \mathrm{i} \mathrm{T}$ en la mesura que implica, ja per si mateixa, una diferència generacional entre els seus membres i que, per tant, el seu expandiment amb descendents comporta una diferència generacional d'almenys dues generacions.

Els expandiments d'aquestes formes elementals poden ser de diverses menes. Sense aspirar a una pretensió d'exhaustivitat, cal notar la pertinència de certs criteris d'expandiment:

1. L'ascendència (a).

2. La descendència (d).

3. La collateralitat (c).

4. Hostes (h).

5. Servents (s).

Fem dues remarques sobre aquests criteris. En primer lloc, l'ascendència i la descendència són dos aspectes complementaris d'un mateix fenomen: la filiació. En segon lloc, deixarem de considerar aquí els criteris 4 i 5 , atès que no són de la mateixa índole que els precedents, basats tots ells en el parentiu - que és el fenomen que bàsicament ens interessa en el 
present context- i així mateix a causa de la minva de llur importància en la societat contemporània.

La combinació de les formes elementals $\mathrm{CP}, \mathrm{N}$ i T amb els criteris d'expandiment 1,2 i 3 , dóna lloc a la taula de combinacions següent:

1.

CP

$\mathrm{CPa} \quad \mathrm{CPd} \quad \mathrm{CPc}$

CPad CPac CPdc

CPadc

2.

N

$\mathrm{Na} \quad \mathrm{Nd} \quad \mathrm{Nc}$

$\mathrm{Nad} \mathrm{Nac} N \mathrm{Ndc}$

$\mathrm{Nadc}$

3.

$\begin{array}{lll}\text { T } & & \\ \text { Ta } & \text { Td } & \text { Tc } \\ \text { Tad } & \text { Tac } & \text { Tdc } \\ \text { Tadc } & & \end{array}$

Acabem d'exposar ací els principis generals en què es basa el nostre sistema classificatori dełs grups residencials. La combinació de les modalitats, formes i criteris esmentats podria produir un nombre de possibilitats molt considerable. Encara que algunes de les categories abans mencionades d'aquesta classificació poden resultax en part supètfues en l'anàlisi de comunitats petites, poden ésser, gràcies a les possibilitats que brinda la in. formàtica, de gran utilitat en l'àmbit d'una ciutat de població elevada. Tot i això, com que la nostra intenció no és esgotar el conjunt de les opcions lògiques, sinó proposar un esquema operatiu fàcilment aplicable a la societat catalana actual, ens veiem obligats a ressaltar aquelles possibles constellacions residencials més freqüents $i / o$ significatives des del punt de vista sociològic. Partint dels elements que hem presentat, les unitats $\circ$ grups residencials es poden agençar segons la classificació següent: 
1. Solitaris (S): Unitat residencial formada per un individu que no comparteix el seu habitatge amb altres persones.

2. Persones no relacionades (PNR): Grups residencials formats per persones que conviuen sense estar lligades entre elles per telacions de parentiu o d'aliança matrimonial.

3. Persones relacionades sense nucli matrimonial (PRSN): Grups residencials que comprenen tota mena de parents (per sang o matrimoni), sense que es doni entre dos qualssevol d'ells cap vincle matrimonial, i amb exclusió de la categotia següent. Citem com a exemples d'aquest tipus de grup residencial dues germanes solteres o vídues, un oncle/tia amb un o més nebots, un avi/àvia amb un nét/néta, o bé dos cosins/cosines.

4. Cellules parentals (CP): Grups residencials constituïts, en la seva forma bàsica, per un pare o per una mate divorciat/ada, separat/ada o vidu/vidua que conviu amb fills seus biològics o legalment reconeguts. Dins d'aquesta categoria, cal incloure els gtups residencials producte dels possibles expandiments, enumerats més amunt, de la seva forma elemental.

5. Nuclis sense fills (NSF): Anomenem NSF aquells grups residencials formats per nuclis matrimonials els membres dels quals conviuen sols. Altrament dit, són nuclis matrimonials sense cap mena d'expandiment. ${ }^{6}$

6. Nuclis amb fills (NAF): Anomenem NAF aquells grups residencials formats per nuclis matrimonials que solament $\mathrm{i}$ exclusivament estan expandits amb fills corresidents de l'un o d'ambdós cònjuges.

7. Nuclis sense fills expandits (NSFE): Anomenem NSFE aquells grups residencials formats per nuclis matrimonials sense fills, però que tenen un expandiment per ascendència $1 / 0$ collateralitat.

8. Nuclis amb fills expandits (NAFE): Anomenem NAFE aquells

6. Es convenient remarcar que les categories 5 a 8 (NSF, NAF, NSFE i NAFE, respectivament) tenen les seves correspondències en el conjunt de combinacions lògiques possibles d'expandiment dels nuclis matrimonials $(\mathrm{N})$ :
5. NSF
$\mathrm{N}$
6. NAF
Nd
7. NSFE
$\mathrm{Na}, \mathrm{Nc}, \mathrm{Nac}$
8. NAFE
Nad, Ndc, Nadc

Aitrament dit:

\begin{tabular}{|c|c|c|c|}
\hline NSFE & $=$ & NSF & 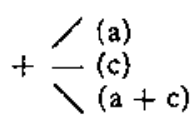 \\
\hline IAFE & $=$ & NAF & $+\frac{\gamma(a)}{(c)}$ \\
\hline
\end{tabular}


geups residencials formats per nuclis matrinoonials amb fills corresidents igualment expandits per ascendència i/o collateralitat. ${ }^{\text {? }}$

9. Família troncal ( $\mathrm{T}$ ): Grup residencial que, en la seva forma bàsica, comprèn dues parelles relacionades per un lligam de filiació. Dins d'aquesta categotia cal incloure els grups residencials troncals expandits en totes llurs possibles variants (vegeu combinatòria més amunt).

10. Altres grups residencials nucleats (AN): Incloem aquesta categoria última per donar cabuda a totes aquelles modalitats residencials no previstes en les categories anteriors ( 5 a 9) (poliginia, dos nuclis matrimonials de la mateixa generació retacionats collateralment, etc.).

L'explotació sociològica d'aquesta classificació exigeix un procés previ de depuració i codificació de les dades contingudes en el padró, que permeti la inclusió de cada full padronal en una categoria determinada. Fins a l'any 1981 els serveis tècnics de certs ajuntaments han procedit a una codificació dels fulls padronals per tipus de grup residencial, inspirant-se generalment en els criteris elaborats per l'INE, $i$ sense posseir necessàtiament una formació que els permetés de fer-ho encertadament. En tals casos la classificació es feia a bell ull, partint de les dades manuscrites que podien suggerir al funcionari la inclusió de tal full padronal en tal categoria. Aquest procediment artesanal, afegit a la imprecisió dels criteris abans esmentats de l'INE, pot conduir a resultats desastrosos $i$, per tant, esdevenir inútil.

El que proposem aquí és, en un primer temps, codificar les informacions manuscrites que defineixen les relacions de cada membre del grup tesidencial (full padronal) amb el cap de casa o persona principal, en funció de la classificació formulada a la taula 1 , i del sexe d'aquests darrets. El mateix agent censal podria realizzar aquesta operació a l'hora d'emplenar o recollir cada full. Els codis numètics, en un segon temps, si s'adopta la nostra proposta, haurien de ser entegistrats sobre suport informàtic. Aleshores l'ordinador procediria a la depuració de les dades brutes, i posaria en relleu les possibles contradiccions entre la relació, ja codificada, amb la persona principal, i altres informacions que poden permetre el seu control, com ara el sexe, l'edat, l'estat civil i la situació residencial, amb el benentès que sols considerem les persones presents $i$ transeünts. ${ }^{8}$

7. La distribució d'aquests quatre apartats $(5$ a 8 ), corresponents a diverses modalitats de grups residencials que comporten un sol nucli matrimonial, obeeix a la necessitat de categotitzar separadament variants d'un mateix tipus estructural, molt freqüents a la societat catalana moderna.

8. Per exemple, una persona casada de «tres anys», una dona, amb dos fills, i de sexe «masculi», $\mathrm{i}$ altres incongruències d'aquesta mena que es trojen efectivament a 
A continuació, l'ordinador aplicaria les instruccions que derivarien de la nostra proposta de classificació de grups tesidencials. Per complex que pogués ser el programa corresponent (car pressuposaria passar d'una perspectiva centrada en un Ego -el sexe del qual cal especificar- a una tipologia de categories no basada en una referència al cap de casa o persona principal), és informàticament factible. El tesultat material d'aquest tractament es presentaria sota la torma d'una distribució estadística que mos. traria la proporció que representa cada tipus de grup residencial en una població determinada.

Per descomptat, aquesta distribució podria ser sotmesa a anàlisis més ptecises segons els casos. De cara als serveis socials, seria d'importància capital conèixer en profunditat les caracteristiques de les cèllules parentals (CP), en particular de les no expandides. L'estudi estadístic independent d'aquesta categoria podria revelar àrees de necessitat social poc conegudes o no expressades. Mencionem, per exemple, les vídues joves amb fills. Esmentem igualment la necessitat de conèixer la situació residencial de les persones velles o disminuides per tal de poder avaluat el grau potencial de suport familiar de què disposen.

D'altra banda, és intetessant, tant des del punt de vista sociològic com des del punt de vista de la planificació sòcio-econòmica, escatir el grau d'associació existent entre determinades composicions dels grups residencials, i la professió i altres característiques (edat, nivell d'instrucció...) de llurs tmembres.

Subratllem que les nostres propostes es poden aplicar sense que hi hagi menyscapte dels drets de privacitat dels enquestats, atès quue en totes aquestes opetacions hom prescindeix de tota referència als noms, cognoms $\mathrm{i}$ adreces.

De tota manera, som conscients de les limitacions que comporta l'aplicació de la nostra tipologia. La principal d'elles rau en el fet que un padró no és més que una imatge estàtica d'una comunitat determinada en un moment precís. No pren en consideració l'origen ni les transformacions que determinen o afecten totes les distribucions estadístiques que resultarien de les anàlisis suggerides en aquest treball. Per exemple, les dades propotcionades per un sol padtó no permeten tenir en compte el cicle de desenvolupament dels grups residencials. La situació d'una pareila sense fills (NSF) pot atribuir-se principaiment a un dels tres factors següents:

l'hora de depurar dades padronals. En aquest cas, existeixen determinades possibilitats: o bé la conjuminació de la totalitat de les dades permet de rectificar l'element incongruent, o bé implica ia invalłdació del full. En aquest lloc, no podem dedicar-nos a exposar les consequències d'aquests problemes. 
a) Un casament neolocal recent, o sia una parella que acaba de formar un grup residencial diferent del dels pares d'ell o d'ella; $b$ ) l'esterilitat; i c) la dispersió dels fills d'una parella d'edat madura.

Podem citar igualment el cas d'un grup nuclear amb fills (NAF), que tant pot haver estat originat per un matrimoni neolocal com pot constituir la fase del cicle de desenvolupament d'una família troncal que segueix la mort dels membres de la generació més anciana.

Així, veiem com la nostra tipologia és insuficient de cara a la comprensió de la gènesi dels grups residencials i de les transformacions de l'es. tructura demogràfica, com pot ser l'envelliment progressiu de la població atribuible al descens de la fertilitat o al trencament dels fluxos migratoris. Per tal de comprendre a fons els processos de canvi de l'organització social, cal introduir una dimensió temporal en l'anàlisi. Això es pot aconseguir de dues formes que poden ser complementàries: adés per una anàlisi comparativa de dos o més padrons successitus, adés per l'examen de les dades fornides per les rectificacions padronals. Com que la mecanització de les dades padronals és tanmateix recent i també a causa de les deficiències en la depuració, la codificació i la classificació dels grups residencials que hem comentat en aquest article, ens centrarem sobtetot en les possibilitats que ofereix l'explotació sistemàtica de les rectificacions padronals.

\section{EL MILLORAMENT I L'EXPLOTACIO DE LES RECTIFICACIONS PADRONALS}

Fins ara els ajuntaments han estat emprant un procediment de rectificació dels padrons per tal d'actualitzar-los. El destí de les dades procedents de les rectificacions ha estat només l'estimació de les variacions de la població en els períodes intercensals $i$, malauradament, la riquesa d'informació que contenen no ha estat prou explotada.

Les rectificacions es refereixen a dues menes d'alteracions. Les primeres, que anomenarem externes, enregistren les entrades $i$ sortides d'individus d'un municipi determinat. Aquestes altes i baixes poden terir un gran interès no sols de cara a l'establiment dels corrents immigratoris i emigratoris, sinó que també ens forneixen informació sobre la tendència a casar-se amb persones que viuen dins o fora del municipi. Les rectificacions internes, és a dir, aquelles que no impliquen l'entrada o la sortida d'un individu de la comunitat, són igualment d'una gtan importància a ihora d'avaluar les transformacions de les estructures demogzàfiques d'un any a l'altre i de comprendre certs processos de mudança en l'organització 
social del municipi. Les rectificacions internes són resultants de certs canvis que delimiter el procés vital de l'individu i que en constitueixen fites importants. Cal citar entre ells el naixement, la mort i els canvis d'estat civiI. Igualment els ajuntaments solen enregistrar els canvis de residència i el pas a la majoria d'edat, dades necesssàries per a la confecció i actualització del cens electoral. En tot cas és preceptiu enregistrar els canvis de qualificació veinal i el pas de presents $i$ transeünts a absents, $i$ viceversa.

Concretament, en els fulls padronals de 1981 que hem consultat, figuten caselles especials, que ha d'emplenar la mateixa administració, referides a les rectificacions sobre les informacions següents:

1. Altes per naixement, immigració, canvi de domicili, omissió, etc.

2. Baixes per defunció, emigració, canvi de domicili, inscripció indeguda, etc.

3. Canvis de qualificació veïnal per causa de majoria d'edat, matrimoni, viduitat, etc.

A més, tot seguit hi observem una casella addicional, que probablement deu emplenar l'agent censal, destinada a precisar, en el cas dels absents, el municipi $i$ província o país estranger on es troben $i$, en el cas dels ttanseünts, el nom del municipi o província on tenen la seva residència habitual. Ignorem l'efectivitat d'aquesta darrera casella que, en tot cas, no sembla donar cabuda a la incorporació de possibles alteracions d'aquestes dades. En tot cas, remarquem que, entre les divetses rectifica" cions, la data dels nous mattimonis no sembla ser enregistrada per dret propi, sinó com una de les causes de canvi de qualificació veïnal, i desconeixem la diligència amb què aquestes dades són enregistrades.

Les rectificacions padronals poden ajudar a posar al dia amb regularitat les modificacions en la composició dels grups residencials que incideixen directament sobre les necessitats de serveis socials i culturals o d'equipaments. Per exemple, la mort d'un dels membres d'un matrimoni d'una certa edat sense parents o suport adequat pot fer necessàries determinades formes d'assistència; o bé l'increment del nombre d'infants d'una llar pot comportar canvis en les necessitats d'habitatge per part de certes famílies.

Les rectificacions padronals, si és que són objecte d'una recollida atenta i regular, permeten superat la visió sincrònica de la realitat social que ofereix l'anàlisi de les dades padronals. El problema és, justament, que l'enregistrament de les rectificacions pot efectuar-se amb retard $o$, fins $i$

9. A títol d'exemple, a l'apènđix II donem el llistat dels elements d'informació de què disposen els serveis tècnics de l'Ajuntament d'una gran ciutat de Catalunya. 
tot, ser deficient. En efecte, nombroses són les causes que contribueixen a reduir la frabilitat de les rectificacions padronals; entre elles es destaquen: a) Retards d'entegistrament de tot tipus deguts a la no comunicació de la circumstància de la variació per part dels mateixos interessats; $b$ ) la falta d'enregistrament de naixements i de defuncions de ciutadans d'un municipi donat, ocorreguts fora d'aquest municipi; c) la falta de la comunicació de la baixa pet part d'aquelles persones que emigren definitivament del mu. nicipi per casar-se o trobar feina o, en el cas d'immigrants jubilats, per retirar-se al poble d'origen.

És clat que resulta molt dificil remeiar sistemàticament aquestes deficiències d'enregistrament sobre una base anual. És prou sabut que les taxes de naixement o de defunció d'un municipi, per citar només aquests exemples, sols es poden determinar amb exactitud amb un retard de dos o tres anys o -el cas no és rar- a l'hora del següent empadronament. Cal dir, però, que eis serveis tècnics no estan totalment desproveits de mitjans per a millorar aquesta situació. El primer pas seria un coneixement més exacte dels errors $i$ dels retards enregistrats durant els cinc anys que precediren l'últim padtó. Aquesta avaluació de les deficiències passades es podria efectuar a partir de la comparació sistemàtica dels canvis de status personal assenyalats pel conjunt de les rectificacions anuals i les informacions relle. vants del padró. Els resultats d'aquesta comparació indicarien precisament quins tipus d'enregistrament haurien de ser objecte d'una vigilància més acurada per part de l'ajuntament en l'esdevenidor. La propaganda ciutadana, enfocada sobretot en el sentit de mostrar als membtes d'una collectivitat la incidència del perfeccionament de les rectificacions en el miJorament dels serveis socials, podria fins a un cert punt contribuir a disminuir els retards d'enregistrament. D'altra banda, la comunicació anual entre els municipis de les informacions referides a dades d'alta i de baixa -intercanvi que possibilitaria la informàtica - constituiria un mitjà prou eficient per a compensar inadvertències personals de certs migrants. En fi, cal subratllar que la tramesa automàtica d'actes de naixement $\mathrm{i}$ de defunció per part dels metges que atesten aquests esdeveniments al lloc de residència dels pares o d'empadronament, respectivament, conduiria a un progrés sensible $\mathrm{i}$ ràpid en el coneixement de dos fenòmens demogràtics tan fonamentals com són la natalitat i la mortalitat.

Si, a partir d'ara, les dades proporcionades per les rectificacions padronals fossin a la vegada:

- més ben revisades anualment;

- contrastades a posteriori, dos anys, per exemple, després de la cloenda del període anual en qüestió, i 
- gravades sobre suport magnètic a mesura que l'administració en tingtués notícia, hom obtindría una eina molt valuosa per a la comprensió no tan sols de les estructures i pautes demogràfiques i sòcio-econòmiques, sinó igualment de llurs principals transformacions. En pocs anys, aquest corpus d'informacions podria facilitar la tasca dels planificadors socials gràcies a les seves qualitats de previsió.

Un tractament adient de les dades proporcionades pels padrons $\mathrm{i}$ llurs rectificacions constitueix una feina bàsica de cara a la determinació de la política municipal tant en l'àmbit cconòmic com en el camp dels serveis socials i culturals. Per tant, caldria encomanat oficialment l'elaboració i l'actualització contínues de les mencionades dades als serveis tècnics dels ajuntaments importants $i$ a les mancomunitats que agrupen els municipis petits. El cost d'aquesta feina de seguiment seria molt inferior a les pèrdues causades pel desencert de decisions elaborades sense una base adequada d'informació prèvia.

\section{CONCLUSIONS}

Tots els procediments d'anàlisi que hem suggerit, si fossin aplicats sistemàticament, suposarien un coneixement de l'organització social que transcenditia de bon tros el que es pot derivar del conjunt d'informacions que hom maneja usualment, tesultant de l'agregació abusiva de dades padronals $i$ censals. És una dissort que la profusió d'informacions contingudes en els padrons i censos es malmeti i que no sigui explotable a nivell municipal. Però, a més, l'aplicació de les tècniques que proposem permetria uItrapassar aquest marc, reduit al mer coneixement de les coordenades formals de l'organització social. En efecte, les dades que posseïm a nivell qualitatiu sobre l'estructuració de les transformacions i dels processos profunds de la realitat catalana són ben escadusseres. Les anàlisis que proposem constitueixen passos previs imprescindibles d'una mena d'indagació més subtil que permeti copsar els canvis en les relacions humanes.

Per illustrar el que volem dir, posem un exemple que afecta la societat catalana en el seu conjunt, i pel que fa al seu esdevenidor. En l'actualitat, s'està desenvolupant un debat força confús a l'entorn de la noció d'«integtació» dels immigrats i de llurs descendents dins la societat catalana. Sense procedir ací a una crítica aprofundida d'aquesta problemàtica, voldríem advertir el fet prou clar de la formació d'una societat catalana en la qual la dicotomia tan feta servir entre catalans autòctons $i$ immigrats 
ja no és pertinent, donada la importància dels contingents cada vegada més nombrosos de fills d'immigrats, nascuts a Catalunya $\mathrm{i}$ imbuits d'una tradició cultural no necessàriament catalana. Es dóna igualment el cas de totes aquelles persones nascudes de matrimonis mixtos, és a dir, contrets entre una persona d'origen català $i$ una altra d'origen foraster.

El coneixement d'aquest procés de mudança tan sobresortint no es podrà assolir exclusivament a través d'un debat ideològic. Com a punt de partida, cal tenir en compte les dades disponibles. ¿De quins municipis d'Espanya han vingut els immigrats a Catalunya des de l'any 1950? ¿A quins camps d'activitat econòmica s'han dedicat en els municipis que els han acollit? ¿Quins moviments migratoris dins de Catalunya s'han donat entre la població immigrada (i autòctona) des de la seva arribada? ¿Quin és el seu nivell d'educació actual? ¿Quina llengua peninsular o estrangera parlaven els immigrats abans de desplaçat-se? ¿Quina/quines llengua/llengües parien avui? ¿Quina és l'amplitud del moviment de retorn de certs immigrants, que ha contribuit a la inversió de la tendència al creixement demogràfic d'alguns municipis de Catalunya en els darrers anys? ¿Quines consequiències demogràfiques $i$ fiscals té per als municipis l'envelliment de la població, i quin pes hi té l'estancament de la immigració a la darreria dels anys setanta?

Quines han estat les pautes matrimonials a Catalunya? Per exemple, ¿fins a quin punt els catalans autòctons i de tradició cultural catalana han tendit a casar-se amb immigtats no catalanoparlants? En aquest cas de matrimoni mixt, quina serà la liengua d'ús en l'àmbit familiar? D'altra banda, fins a quin punt han volgut els immigrats esposar-se amb persones del seu Hoc d'origen o dels voltants o, en canvi, amb altres immigrats de la mateixa regió de procedència que resideixen en el seu barri actual o en pobles veïns? I, en fi, ¿quin és i serà el comportament matrimonial dels descendents d'immigrats $\mathrm{i}$ dels fills de matrimonis mixtos?

De tot això se'n sap ben poc. De les respostes a aquestes preguntes de. pèn el coneixement sobre la possible cristallització de comunitats «biculturals», fenomen que, a la Ilarga, podria conduir a una escissió de la collectivitat catalana. Una estimació exacta de l'evolució de les preferències matrimonials efectuada en funció de les altres qüestions que plantegem, menaria a una comprensió sociològicament fonamentada de fets importantíssims, molt debatuts i poc coneguts. 


\section{APENDIX I}

INFORMACIONS ELEMENTALS

CONTINGUDES EN UN FULL PADRONAL DE 1981

1. Clau (Personai).

2. Districte,

3. Secció.

4. Illa.

5. Ordre.

6. Codi carter.

7. Número de casa.

8. Bis.

9. Quilòmetre.

10. Bloc.

11. Portal.

12. Escala.

13. Pis.

14. Porta.

15. Cognoms i noms $\left(^{*}\right)$ (Nom, cognom primer, cognom segon).

16. Nom dels pares $\left(^{*}\right)$ (Nom del pare, nom de la mare).

17. Situació residencial (Present, absent, transeünt).

18. Parentiu o relació anb el cap de família o la persona principal (*).

19. Sexe (Home, dona).

20. Estat civil (Solter, casat, vidu, divorciat o separat).

21. Municipi de naixement $\left({ }^{*}\right)$.

22. Província de naixement $(*)$.

23. Data de naixement (Dia, mes, any).

* Aquestes informacions figuren al full padronal arab totes les seves Iletres i, per tant, han de ser codificades. El cost tan elevat de llur codificació posterior al cens n'ha invalidat l'explotació fins aza, en molts casos. 
24. Any d'arribada al municipi.

25. Any d'arribada a Catalunya.

26. Nacionalitat $(*)$.

27. Escolar-estudiant (Si, no).

28. Nivell d'instrucció (1 a 8):

1. No sap llegir ni escriure o hi té dificultats.

2. Primària incompleta.

3. Primària o EGB primer cicle complet.

4. Batxillerat elemental o EGB segon cicle complet.

5. Formació professional, oficialia inclosa.

6. Batxilierat superior, mestratge, BUP o COU.

7. Títol grau mitjà.

8. Títol superior.

29. Llengua catalana ( $\left(S_{1}\right.$, no).

30. Situació laboral (1 a 9):

1. Compleix el servei militar.

2. Està trebailant en:

- Un ofici, professió o lloc de treball temunerat.

- Empresa familiar amb quinze o més hotes setmanais no remunerades.

3. Busca ocupació per primera vegada.

4. Està aturat i busca ocupació havent treballat abans.

5. Es retirat, jubilat, pensionista, etc.

6. Viu de tendes, dividends, etc.

7. Assisteix regularment a un centre d'ensenyament.

8. Es dedica exclusivament a les feines de la llar.

9. Està en una altra situació (menor no escolaritzat, etc.).

31. Activitat de l'empresa (*).

32. Professió (*).

33. Condició sòcio-econòmica (1 a 9):

1. Patró, empresari o professional que dóna feina a personal.

2. Empresari o professional que no dóna feina a personal o treballador per compte propi.

3. Membre de cooperativa de producció o de comerç, en la qual treballa. 
4. Persona que treballa amb caràcter fix, a sou, jornal, comissió o una altra classe qualsevol de remuneració.

5. Persona que treballa amb caràcter eventual o interí, a sou, jornal, comissió o una altra classe qualsevol de remuneració.

6. Persona que treballa sense remuneració reglamentada (a l'empresa o negoci d'un familiar, amb qui conviu, etc.).

7. Altres actius, busca feina, compleix el servei militar.

8. Mestressa de casa.

9. No actius: estudiant, escolar, menor, jubilat, rendista, incapacitat laboral, etc.

34. Manera de realitzar l'activitat principal ( 1 a 6 ):

1. Realitza el seu treball principal en un lloc concret, fora de casa (fàbrica, taller, obra, hort, etc.).

2. Assisteix a un centre docent (universitat, escola, guardexia).

3. Té a fora de casa el centre de treball, del qual es desplaça a altres llocs per taó de feina (installador de telèfons, empleat de companyies de gas i d'electricitat, conductor d'autobús, etc.).

4. Surt fora de casa per realitzar el seu treball, però sense destinació fixa diària (taxista, viatjant, visitador domiciliari, etc.).

5. Realitza el seu treball principal al mateix edifici on viu.

6. No està obligat a desplaçar-se per a treballat o estudiar, perquè no és actiu, [és] jubilat, es dedica a les feines de casa, està en atur o fa el servei militat.

35. Localització de l'activitat principal (Nom de l'empresa, carrer, númemero, municipi, telèfon).*

36. Mitjà de transport ( 1 a 8$)$ :

1. Metro.

2. Bus.

3. Tren.

4. Bus d'empresa o bus escolar.

5. Transport individual (cotxe, moto).

6. Taxi.

7. A peu.

8. No es desplaça. 
«Papers»: Revista de Sociologia

37. Qualificació veinal.**

38. Disminució (física, d'altres).***

** Ignorem el motiu de la inclusió d'aquesta informació d'índole arcaica..., que segurament desapareixerà del padró amb l'elaboració d'una nova llei de règim local. *** No cal tenir gaires coneixements en matèria de serveis socials per a dubtat de la competència deIs serveis tècnics que formularen la distincio, totalment inoperativa, entre «disminuilts físics» $i$ «d'altres». És ben bé una tlàstima que hom hagi desaprofitat una ocasió tan valuosa d'obtenir informacions sistemàtiques sobre un problema tan apressant. 


\section{APENDIX $I$}

INFORMACIONS ENREGISTRADES EN CONCEPTE DE RECTIFICACIONS PELS SERVEIS TÈCNICS D'Un Ajuntament de Catalunya

1. Data de l'alta.

2. Data de la baixa.

3. Data del casament.

4. Data de la defunció.

5. Data de l'últim canvi de domicili.

6. Data del pas d'absent a present.

7. Indicació de l'estat d'absent/present.

8. Any de naixement.

9. Data de canvi de l'estat civil.

10. Nou estat civil.

11. Motiu de l'alta.

12. Motiu de la baixa.

13. Barriada.

14. Barri. 